\title{
Perioperative Immune Checkpoint Inhibitors in Renal Cell and Urothelial Carcinomas: An Exciting New Paradigm under Investigation?
}

\author{
Carlo Buonerba ${ }^{\text {a, b, c }}$ Petros Grivas $^{d}$ Giuseppe Di Lorenzo a, e

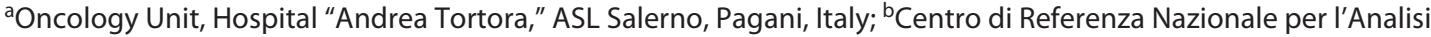 \\ e Studio di Correlazione tra Ambiente, Animale e Uomo, Istituto Zooprofilattico Sperimentale del Mezzogiorno, \\ Portici, Italy; ${ }^{C}$ Associazione O.R.A., Somma Vesuviana, Naples, Italy; ${ }^{d}$ Fred Hutchinson Cancer Research Center, \\ Seattle Cancer Care Alliance, University of Washington, Seattle, WA, USA; ${ }^{\text {eDepartment }}$ of Medicine \& Health \\ Science, University of Molise, Campobasso, Italy
}

Kidney cancer and bladder cancer were responsible for about half of the approximately 800,000 deaths related to genitourinary malignancies estimated worldwide in 2020 [1]. Bladder cancer is more frequent in men, with an agestandardized incidence rate of 9.5 cases per 100,000 men versus 2.4 cases per 100,000 women worldwide. Conversely, the age-standardized incidence rate of kidney cancer is 6.1 per 100,000 men and 3.2 per 100,000 women. Despite differences in the etiology, pathogenesis, and other used therapies, renal cell carcinoma (RCC) and urothelial carcinoma can be sensitive to immune checkpoint inhibitors (ICIs), which have considerably improved the prognosis of patients with advanced disease.

In patients with advanced urothelial cancer, the use of second-line anti-programmed death 1 (PD-1) agent pembrolizumab yielded a significant $27 \%$ reduction in the risk of death compared to taxane or vinflunine chemotherapy in patients with platinum-refractory disease [2], while anti-programmed death ligand 1 (PD-L1) avelumab yielded a $31 \%$ reduction in the risk of death as switch maintenance therapy in patients without progression after induction platinum-based chemotherapy in the firstline setting [3]. Both agents have full FDA approval in the platinum-refractory and the maintenance first-line set-

karger@karger.com

(c) 2021 S. Karger AG, Basel

www.karger.com/oc

Karger! ting, respectively, supported by level I evidence. Moreover, pembrolizumab and the anti-PD-L1 agent atezolizumab have accelerated FDA approval as first-line systemic therapy in patients with advanced urothelial cancer who are cisplatin ineligible and have tumors harboring high PD-L1 expression (and platinum-ineligible patients regardless of PD-L1 in the USA only) [4]. Updated results of the single-arm phase II KEYNOTE-052 trial of pembrolizumab as the first-line therapy in cisplatin-ineligible patients with urothelial carcinoma showed an overall response rate of $29 \%$ (95\% CI: $24.3-33.8$ ) with a median overall survival (OS) of 11.3 months (95\% CI: 9.7-13.1) [5].

In clear cell RCC, first-line pembrolizumab + antiVEGF agent axitinib was associated with a significant $27 \%$ reduction in the risk of death compared to sunitinib in a phase III trial [6]. The anti-PD-1 agent nivolumab + anti-cytotoxic T-lymphocyte antigen 4 agent ipilimumab significantly prolonged OS compared to sunitinib in a phase III trial in patients with poor or intermediate IMDC risk [7]. Significant OS and PFS improvements have also been reported in phase III trials with cabozantinib/ nivolumab and pembrolizumab/lenvatinib, compared to sunitinib, respectively [8]. 
Although patients with RCC and urothelial carcinoma are often at high risk of recurrence after radical surgery based on pathologic stage, little progress had been made in the perioperative setting till recently, with many trials either having design flows and/or being underpowered to definitely elucidate the role of adjuvant cisplatin-based chemotherapy in urothelial carcinoma of the bladder [9]. More recently, the results of the phase III POUT trial showed that adjuvant cisplatin or carboplatin (although the vast majority of patients received cisplatin) with gemcitabine was associated with a 55\% reduction in the risk of recurrence or death in patients with fully resected urothelial carcinoma of the upper urinary tract [10]. More recently, the findings from the phase III Checkmate 274 trial in patients enrolled after radical cystectomy or (nephro)-ureterectomy for muscle-invasive urothelial cancer were reported [11]. In that trial, adjuvant nivolum$\mathrm{ab}$ for a year was associated with a median disease-free survival (DFS) of 20.8 versus 10.8 months with placebo, with a significant hazard ratio (HR) for recurrence or death of 0.70 (98\% CI: 0.55-0.90; $p<0.001$ ); HR was lower $(0.55$ [98\% CI: $0.35-0.85 ; p<0.001])$ in patients with PD-L1-high tumors. The grade $3-5$ treatment-related adverse event rate associated with nivolumab was about $18 \%$, with the most common serious adverse events being elevation of lipase (5.1\%) and amylase (3.7\%). Toxicity leading to treatment discontinuation was reported in $12.8 \%$ of patients with nivolumab, while 2 patients $(0.5 \%)$ died because of nivolumab-induced pneumonitis. Patient-reported outcomes did not show deterioration of quality of life with adjuvant nivolumab. The FDA decision is expected by September 2021, although mature OS data are not available yet.

Additionally, a properly powered investigation is required to establish whether certain patient subsets may derive greater benefit from adjuvant nivolumab. In this regard, an exploratory subgroup analysis of patients with prior neoadjuvant cisplatin-based chemotherapy showed a HR 0.51 for DFS, favoring nivolumab versus placebo [12]. Although exploratory subgroup post hoc analysis must be interpreted with high caution and considered only as hypothesis generating, this difference may potentially reflect an optimal sequence of adjuvant ICI after neoadjuvant cisplatin-based chemotherapy. From a biologic standpoint, it can be considered that neoadjuvant cisplatin-based therapy may reduce regulatory $\mathrm{T}$ cells (Tregs), as shown in a clinical study of 40 patients with non-small cell lung cancer, which reported increased levels of CD4(+)CD25(+)FOXP3(+) and CD8(+)CD28(-) Tregs in patients with progressive disease and decreased levels following gemcitabine/cisplatin [13]. Also, it must be noted that in the phase III IMvigor010 trial, adjuvant atezolizumab versus observation was associated with a median DFS of 19.8 versus 16.5 months in patients who had prior neoadjuvant chemotherapy as opposed to 16.8 versus 19.4 months in patients who had not received neoadjuvant chemotherapy [14]. However, that trial was not powered to assess those differences and the impact of neoadjuvant chemotherapy on adjuvant ICIs. Conversely, a significant interaction was found between atezolizumab efficacy and presence of detectable circulating tumor DNA at baseline, which was associated with HR 0.58 for DFS (95\% CI: 0.43-0.79) and HR 0.59 for OS (95\% CI: 0.41-0.86) [15]. Prospective clinical trials, such as IMvigor011, are required to assess whether adjuvant atezolizumab can show confirmed DFS and/or OS benefit in selected patients based on present circulating tumor DNA.

The KEYNOTE-564 trial showed that in patients with clear cell RCC, including 58 patients with no detectable disease after resection of oligometastatic disease (M1) and 936 patients with nonmetastatic (M0) high-risk disease randomized to a year of pembrolizumab or placebo after radical surgery, pembrolizumab significantly prolonged DFS (HR 0.68, 95\% CI: 0.53-0.87), as well as OS (HR 0.54, 95\% CI; 0.30-0.96) versus placebo, although the OS data were immature and longer follow-up is needed [16]. Although the subgroup of patients with M1 disease was very small $(<10 \%)$ in the KEYNOTE-564 trial, a hypothesis-generating DFS benefit clearly emerged, with the HR for DFS 0.29 (95\% CI: 0.12-0.69) in patients with fully resected M1 stage. Additional valuable data in the perioperative setting will be provided by the PROSPER trial [17], which is assessing the use of nivolumab administered both pre- and postoperatively in patients with RCC undergoing radical surgery, as well as other important perioperative trials.

It is conceivable that the use of perioperative versus postoperative-only ICI may be advantageous given the high antigen load associated with the presence of the primary tumor, which may trigger immune response [18]. Another question is the evaluation of combination therapies in the perioperative setting, for example, ICI with anti-VEGF agent for RCC or antibody-drug conjugate or chemotherapy for urothelial cancer. Although trials are being conducted and require accrual (Table 1), we foresee that further potential breakthrough data may be provided in the future by combination trials in the perioperative setting (before and after radical surgery), assuming the combinations are safe. Moreover, the evaluation of pathologic response to preoperative/neoadjuvant therapy may 
Table 1. Examples of ongoing perioperative phase III ICI trials in bladder and kidney cancer

\begin{tabular}{|c|c|c|c|c|}
\hline Title & $\begin{array}{l}\text { Primary } \\
\text { endpoint(s) }\end{array}$ & Interventional arm(s) & Control arm(s) & $\begin{array}{l}\text { Estimated } \\
\text { enrollment } \\
\text { goal }\end{array}$ \\
\hline $\begin{array}{l}\text { Durvalumab + Gemcitabine/Cisplatin (Neoadjuvant } \\
\text { Treatment) and Durvalumab (Adjuvant Treatment) in } \\
\text { Patients With MIBC (NIAGARA) }\end{array}$ & $\begin{array}{l}\text { pCR } \\
\text { EFS }\end{array}$ & $\begin{array}{l}\text { Durvalumab + gemcitabine/cisplatin } \\
\text { (neoadjuvant treatment) and durvalumab } \\
\text { (adjuvant treatment) }\end{array}$ & $\begin{array}{l}\text { Gemcitabine/cisplatin } \\
\text { (neoadjuvant } \\
\text { treatment) }\end{array}$ & 1,050 \\
\hline $\begin{array}{l}\text { A Study of Chemotherapy Only Versus Chemotherapy } \\
+ \text { Nivolumab With or Without BMS-986205, Followed } \\
\text { by Post-Surgery Therapy With Nivolumab or } \\
\text { Nivolumab and BMS-986205 in Patients With MIBC }\end{array}$ & $\begin{array}{l}\mathrm{pCR} \\
\mathrm{EFS}\end{array}$ & $\begin{array}{l}\text { BMS- } 986205 \text { placebo + nivolumab + } \\
\text { chemotherapy followed by BMS- } 986205 \\
\text { placebo + nivolumab postradical cystectomy } \\
\text { BMS- } 986205+\text { nivolumab + chemotherapy } \\
\text { followed by nivolumab + BMS- } 986205 \\
\text { postradical cystectomy }\end{array}$ & $\begin{array}{l}\text { Chemotherapy alone } \\
\text { followed by radical } \\
\text { cystectomy }\end{array}$ & 1,200 \\
\hline $\begin{array}{l}\text { Perioperative Pembrolizumab (MK-3475) + } \\
\text { Neoadjuvant Chemotherapy Versus Perioperative } \\
\text { Placebo + Neoadjuvant Chemotherapy for Cisplatin- } \\
\text { eligible Muscle-invasive Bladder Cancer (MIBC) } \\
\text { (MK-3475-866/KEYNOTE-866) (KEYNOTE-866) }\end{array}$ & $\begin{array}{l}\text { pCR } \\
\text { EFS }\end{array}$ & $\begin{array}{l}\text { Pembrolizumab + gemcitabine }+ \text { cisplatin } \\
+ \text { surgery + adjuvant pembrolizumab }\end{array}$ & $\begin{array}{l}\text { Placebo + gemcitabine } \\
+ \text { cisplatin + surgery }+ \\
\text { adjuvant } \\
\text { pembrolizumab }\end{array}$ & 870 \\
\hline $\begin{array}{l}\text { Perioperative Pembrolizumab (MK-3475) + } \\
\text { Cystectomy or Perioperative Pembrolizumab + } \\
\text { Enfortumab Vedotin + Cystectomy Versus } \\
\text { Cystectomy Alone in Cisplatin-ineligible Participants } \\
\text { With Muscle-invasive Bladder Cancer (MK-3475-905/ } \\
\text { KEYNOTE-905/EV-303) }\end{array}$ & $\begin{array}{l}\mathrm{pCR} \\
\mathrm{EFS}\end{array}$ & $\begin{array}{l}\text { Neoadjuvant pembrolizumab }+ \text { surgery }+ \\
\text { adjuvant pembrolizumab } \\
\text { Neoadjuvant enfortumab vedotin }+ \\
\text { pembrolizumab + surgery followed by } \\
\text { enfortumab vedotin }+ \text { pembrolizumab and } \\
\text { pembrolizumab }\end{array}$ & Surgery alone & 836 \\
\hline $\begin{array}{l}\text { Testing the Addition of an Anti-Cancer } \\
\text { Immunotherapy Drug, Avelumab, to Gemcitabine and } \\
\text { Carboplatin Chemotherapy Prior to Surgery in } \\
\text { Muscle-Invasive Urinary Tract Cancer versus Surgery } \\
\text { Alone in Patients Who Are Not Able to Receive } \\
\text { Cisplatin Therapy (SWOG GAP TRIAL) }\end{array}$ & $\mathrm{pCR}$ & $\begin{array}{l}\text { Avelumab, gemcitabine, carboplatin, } \\
\text { surgery }\end{array}$ & Surgery & 196 \\
\hline $\begin{array}{l}\text { Testing MK-3475 (Pembrolizumab) After Surgery for } \\
\text { Localized Muscle-Invasive Bladder Cancer and Locally } \\
\text { Advanced Urothelial Cancer (AMBASSADOR) }\end{array}$ & $\begin{array}{l}\text { OS } \\
\text { DFS }\end{array}$ & Cystectomy + pembrolizumab & Pembrolizumab & 739 \\
\hline $\begin{array}{l}\text { A Study of Nivolumab Plus Bempegaldesleukin } \\
\text { (Bempeg/NKTR-214) versus Nivolumab Alone versus } \\
\text { Standard of Care in Participants With Bladder Cancer } \\
\text { That Has Invaded the Muscle Wall of the Bladder and } \\
\text { Who Cannot Get Cisplatin, a Type of Medicine Given } \\
\text { to Treat Bladder Cancer }\end{array}$ & $\begin{array}{l}\text { pCR after } \\
\text { neoadjuvant } \\
\text { treatment } \\
\text { EFS }\end{array}$ & $\begin{array}{l}\text { Neoadjuvant nivolumab + bempeg, } \\
\text { followed by radical cystectomy, followed by } \\
\text { adjuvant (postsurgical treatment) } \\
\text { nivolumab + bempeg } \\
\text { Neoadjuvant nivolumab, followed by } \\
\text { radical cystectomy, followed by adjuvant } \\
\text { nivolumab }\end{array}$ & $\begin{array}{l}\text { Radical cystectomy } \\
\text { alone, without } \\
\text { neoadjuvant or } \\
\text { adjuvant therapy }\end{array}$ & 540 \\
\hline $\begin{array}{l}\text { Perioperative Enfortumab Vedotin (EV) Plus } \\
\text { Pembrolizumab (MK-3475) Versus Neoadjuvant } \\
\text { Chemotherapy for Cisplatin-eligible Muscle-Invasive } \\
\text { Bladder Cancer (MIBC) (MK-3475-B15/ } \\
\text { KEYNOTE-B15/EV-304) (KEYNOTE-B15) }\end{array}$ & $\begin{array}{l}\text { pCR } \\
\text { EFS }\end{array}$ & $\begin{array}{l}\text { Perioperative enfortumab vedotin }+ \\
\text { pembrolizumab and radical cystectomy }\end{array}$ & $\begin{array}{l}\text { Neoadjuvant } \\
\text { chemotherapy } \\
\text { (gemcitabine }+ \\
\text { cisplatin) and radical } \\
\text { cystectomy }\end{array}$ & 784 \\
\hline $\begin{array}{l}\text { A Study Comparing Nivolumab, Nivolumab in } \\
\text { Combination With Ipilimumab and Placebo in } \\
\text { Participants With Localized Kidney Cancer Who } \\
\text { Underwent Surgery to Remove Part of a Kidney } \\
\text { (CheckMate 914) }\end{array}$ & $\begin{array}{l}\text { DFS } \\
\text { OS }\end{array}$ & $\begin{array}{l}\text { Nivolumab + ipilimumab + Nephrectomy } \\
\text { Nivolumab + nephrectomy }\end{array}$ & $\begin{array}{l}\text { Placebo + } \\
\text { nephrectomy }\end{array}$ & 1,600 \\
\hline $\begin{array}{l}\text { Comparing the Outcome of Immunotherapy-Based } \\
\text { Drug Combination Therapy With or Without Surgery } \\
\text { to Remove the Kidney in Metastatic Kidney Cancer, } \\
\text { the PROBE Trial (PROBE) }\end{array}$ & OS & $\begin{array}{l}\text { Nivolumab } \\
\text { OR pembrolizumab + axitinib } \\
\text { OR avelumab + axitinib + nephrectomy }\end{array}$ & $\begin{array}{l}\text { Nivolumab } \\
\text { OR pembrolizumab + } \\
\text { axitinib } \\
\text { OR avelumab + } \\
\text { axitinib }\end{array}$ & 364 \\
\hline
\end{tabular}


Table 1 (continued)

\begin{tabular}{llcc}
\hline Title & $\begin{array}{l}\text { Primary } \\
\text { endpoint(s) }\end{array}$ & $\begin{array}{l}\text { Interventional arm(s) } \\
\text { Control arm(s) }\end{array}$ & $\begin{array}{l}\text { Estimated } \\
\text { enrollment } \\
\text { goal }\end{array}$ \\
\hline $\begin{array}{l}\text { A Study of Atezolizumab as Adjuvant Therapy in } \\
\begin{array}{l}\text { Participants With Renal Cell Carcinoma (RCC) at } \\
\text { High Risk of Developing Metastasis Following }\end{array}\end{array}$ & DFS & Atezolizumab + nephrectomy & $\begin{array}{l}\text { Placebo + } \\
\text { nephrectomy }\end{array}$ \\
$\begin{array}{l}\text { Nephrectomy (IMmotion010) } \\
\begin{array}{l}\text { Nivolumab in Treating Patients With Localized } \\
\text { Kidney Cancer Undergoing Nephrectomy }\end{array}\end{array}$ & EFS & Nivolumab + nephrectomy & $\begin{array}{l}\text { Placebo + } \\
\text { nephrectomy }\end{array}$ \\
\hline
\end{tabular}

pCR, pathologic complete response; EFS, event-free survival; OS, overall survival.

act as a potential indirect indicator of tumor biology and of responsiveness to therapy. However, the composite endpoint of pathologic complete response and event-free survival (with more weight placed on the latter co-primary endpoint, with split of the alpha) appears a reasonable surrogate and metric of a positive perioperative trial for regulatory decisions. However, the surrogacy of those endpoints regarding OS has not been demonstrated yet in the setting of perioperative ICIs. OS, although it is the ideal endpoint, may also be impacted by subsequent treatments, duration of follow-up, competing risks of death, and other confounding prognostic factors. The endpoint of OS may also be hard to assess within a meaningful time frame from the trial launch, considering the continuous improvement of prognosis and the required number of events. Moreover, perioperative clinical trials may provide a great setting for the discovery and validation of biomarkers aiming to select patients who may benefit the most from a particular therapy. The variability in assays/ platforms, time points of biospecimen collection, (pre) analytical methods, and clinical variables renders biomarker validation very difficult. Additional considerations include the impact on subsequent salvage therapy options, for example, re-challenge with ICI, especially if the recurrence occurs much later after completion of (neo)adjuvant ICI therapy, reimbursement, cost and cost-effectiveness, patient-reported outcomes and quality of life, patient convenience, provider comfort, and the huge challenge of access to therapy and existing healthcare disparities.

To conclude, the use of adjuvant single-agent ICIs has significantly extended DFS in patients with clear cell RCC and urothelial carcinoma after radical surgery, while decisions regarding regulatory approvals are anticipated soon. In that context, the potential use of ICI in combination with other active anti-neoplastic agents in the peri- operative (both neoadjuvant and adjuvant) setting may hold promise for even greater benefit and substantial increase of the cure rates. Pathologic complete response rate combined with event-free survival appears as suitable co-primary endpoints in this setting for regulatory purposes, while improvement in OS, despite being the ideal endpoint, may be hard to show within a certain time frame. Finally, patient selection using promising biomarkers (e.g., circulating tumor DNA) has great potential to enrich for a population and optimize benefit and costeffectiveness in the perioperative ICI setting, especially for urothelial cancer. Our assumptions are being tested in ongoing phase 3 clinical trials that require accrual and follow-up.

\section{Acknowledgment}

The authors wish to thank Ms. Ilaria Ascione for her moral support for the preparation of the manuscript.

\section{Conflict of Interest Statement}

Dr. Grivas (in the last 3 years) has provided consulting to AstraZeneca, Bayer, Bristol Myers Squibb, Clovis Oncology, Dyania Health, Driver, EMD Serono, Exelixis, Foundation Medicine, Genentech/Roche, Genzyme, GlaxoSmithKline, Heron Therapeutics, Immunomedics/Gilead, Infinity Pharmaceuticals, Janssen, Merck \& Co., Mirati Therapeutics, Pfizer, QED Therapeutics, Regeneron Pharmaceuticals, Seattle Genetics, and 4D Pharma PLC; his institution has received research funding from Bavarian Nordic, Bristol Myers Squibb, Clovis Oncology, Debiopharm, GlaxoSmithKline, Immunomedics, Kure It Cancer Research, Merck \& Co., Mirati Therapeutics, Pfizer, and QED Therapeutics. Dr. Buonerba (in the last 3 years) has provided consulting to Ipsen. His institution has received research funding from Sanofi, Astellas, and AstraZeneca. Dr. Di Lorenzo serves as an editorial board member of Oncology. 


\section{Funding Sources}

No funding source was used for the preparation of this article.

\section{Author Contributions}

All authors equally contributed to the article.

\section{References}

1 WHO. Available from: https://www.iarc. who.int/.

2 Bellmunt J, de Wit R, Vaughn DJ, Fradet Y, Lee JL, Fong L, et al. Pembrolizumab as second-line therapy for advanced urothelial carcinoma. N Engl J Med. 2017;376(11):101526.

3 Powles T, Park SH, Voog E, Caserta C, Valderrama $\mathrm{BP}$, Gurney $\mathrm{H}$, et al. Avelumab maintenance therapy for advanced or metastatic urothelial carcinoma. N Engl J Med. 2020; 383(13):1218-30.

4 Suzman DL, Agrawal S, Ning YM, Maher VE, Fernandes LL, Karuri S, et al. FDA approval summary: atezolizumab or pembrolizumab for the treatment of patients with advanced urothelial carcinoma ineligible for cisplatincontaining chemotherapy. Oncologist. 2019; 24(4):563-9.

5 O’Donnell PH, Balar AV, Vuky J, Castellano D, Bellmunt, PowlesT, et al. First-line pembrolizumab (pembro) in cisplatin-ineligible patients with advanced urothelial cancer (UC): response and survival results up to five years from the KEYNOTE-052 Phase 2 Study. J Clin Oncol. 2021;39(15 Suppl):4508.

6 Rini BI, Plimack ER, Stus V, WaddellT, GafanovR, PouliotF, et al. Pembrolizumab (pembro) + axitinib (axi) versus sunitinib as first-line therapy for advanced clear cell renal cell carcinoma (ccRCC): results from 42-month follow-up of KEYNOTE-426. J Clin Oncol. 2021;39(15 Suppl):4500.
7 Albiges L, Tannir NM, Burotto M, D, ER, P, et al. Nivolumab + ipilimumab versus sunitinib for first-line treatment of advanced renal cell carcinoma: extended 4-year follow-up of the phase III CheckMate 214 trial. ESMO Open. 2020;5(6):e001079.

8 Heo JH, Park C, Ghosh S, Park SK, Zivkovic M, Rascati KL. A network meta-analysis of efficacy and safety of first-line and second-line therapies for the management of metastatic renal cell carcinoma. J Clin Pharm Ther. 2021; 46(1):35-49.

9 Leow JJ, Martin-Doyle W, Rajagopal PS, CG, EM, AT, et al. Adjuvant chemotherapy for invasive bladder cancer: a 2013 updated systematic review and meta-analysis of randomized trials, Eur Urol. 2014 Jul;66(1):42-54.

10 Birtle A, Johnson M, Chester J, Jones R, Dolling D, Bryan RT, et al. Adjuvant chemotherapy in upper tract urothelial carcinoma (the POUT trial): a phase 3, open-label, randomised controlled trial. Lancet. 2020; 395(10232):1268-77.

11 Bajorin DF, Witjes JA, Gschwend JE, Schenker M, Valderrama BP, Tomita Y, et al. Adjuvant Nivolumab versus Placebo in MuscleInvasive Urothelial Carcinoma. $\mathrm{N}$ Engl J Med. 2021;384(22):2102-14.

12 Bajorin DF, Witjes JA, Gschwend JE, Schenker M, Valderrama BP, Tomita Y, et al. Adjuvant nivolumab versus placebo in muscle-invasive urothelial carcinoma. $\mathrm{N}$ Engl J Med. 2021;384(22):2102-14.
13 Chen C, Chen Z, Chen D, Zhang B, Wang Z, Le H. Suppressive effects of gemcitabine plus cisplatin chemotherapy on regulatory $\mathrm{T}$ cells in nonsmall-cell lung cancer. J Int Med Res. 2015;43(2):180-7.

14 Bellmunt J, Hussain M, Gschwend JE, Albers P, Oudard S, Castellano D, et al. Adjuvant atezolizumab versus observation in muscleinvasive urothelial carcinoma (IMvigor010): a multicentre, open-label, randomised, phase 3 trial. Lancet Oncol. 2021;22(4):525-37.

15 Powles T, Assaf ZJ, Davarpanah N, R, BE, KC, et al. ctDNA guiding adjuvant immunotherapy in urothelial carcinoma. Nature. $2021 \mathrm{Jul}$; 595(7867):432-7.

16 Choueiri TK, P, Park SH, B, T, Y-H, et al. Pembrolizumab versus placebo as post-nephrectomy adjuvant therapy for patients with renal cell carcinoma: randomized, doubleblind, Phase III KEYNOTE-564 Study. J Clin Oncol. 2021;39(15 Suppl):LBA5.

17 Harshman LC, Drake CG, Haas NB, Manola J, Puligandla M, Signoretti S, et al. Transforming the perioperative treatment paradigm in non-metastatic RCC-A possible path forward. Kidney Cancer. 2017;1(1):31-40.

18 Topalian SL, Taube JM, Pardoll DM. Neoadjuvant checkpoint blockade for cancer immunotherapy. Science. 2020;367(6477): eaax0182. 